\title{
Competency Requirements for Managing Public Private Partnerships (PPPs): The Case of Infrastructure Projects in Jordan
}

\author{
Ali M. Mistarihi ${ }^{1,2}$, Mohammad S. Al Refai ${ }^{3}$, Bader Ayed Al Qaid ${ }^{3}$ \& Marzouq A. Qeed $^{4}$ \\ ${ }^{1}$ Yarmouk University, Irbid, Jordan \\ ${ }^{2}$ Griffith University, Queensland, Australia \\ ${ }^{3}$ Department of Business Administration, Irbid National University, Irbid, Jordan \\ 4 The World Islamic Sciences \& Education University, Amman, Jordan \\ Correspondence: Ali Mohammad Mistarihi, Public Administration Department, Yarmouk University, Irbid, \\ Jordan. Tel: 962-077-608-8727. E-mail: amali997@yahoo.com, ali.mistarihi@yu.edu.jo
}

Received: March 16, 2012 Accepted: April 16, 2012 Online Published: June 16, 2012

doi:10.5539/ijbm.v7n12p60

URL: http://dx.doi.org/ijbm.v7n12p60

\begin{abstract}
Managing public-private partnership (PPP), particularly in the implementation phase, is both theoretically and practically complex with success largely determined by how well partnerships are managed. Yet, several PPP scholars have noted that little is known about the management competency requirements to effectively manage in a PPP settings; that is described as different from traditional hierarchical 'command-and-control' management forms, and have called for further research to understand this 'black box'. This research has provided a wide-ranging account of the most significant 'soft-management' competency requirements to effectively mange in such a multi-organizational environment. It is suggested that PPP managers should be able to cope with, adapt to and be flexible to respond to changes that are frequent occurrences during the course of the partnership. Being patient and self-motivated were also qualities PPP managers should possess. Social and interpersonal skills, 'scoping in/out' ability, conceptual skills, project management skills, and, communication and coordination skills were also sets of skills important to effectively manage in a PPP settings. Further, PPP managers should also have sufficient technical and project management experience, as well as experience in negotiation and arbitration. PPP managers should be knowledgeable and qualified to manage the construction, operational and the financial aspects of the PPP project. They should also be familiar with, and use specialized programming and scheduling techniques. The findings of this research were based on data collected from in-depth interviews with 21 partner managers in two case study organizations in Jordan.
\end{abstract}

Keywords: PPP management, PPP competency, PPP skill requirements, PPPs in Jordan

\section{Introduction}

Over the past twenty five years, public private partnerships (PPPs), also known as 'P3s', 'the third way' and 'Private Finance Initiatives (PFIs), have been internationally used as new avenues for providing the public with goods and services. Over 1,100 projects worth US\$ 450 billion built around the globe using one or more PPP forms (Siemiatycki, 2010). Managing PPPs, however, particularly in the implementation phase, is both theoretically and practically complex with success largely determined by how well partnerships are managed (Grossman, 2010). Several PPP scholars (e.g. Bach \& Whitehill, 2008; Jones \& Noble, 2008) have noted that little is known about the management phase of PPP projects and called for further research to understand this 'black box' of PPPs (e.g. Weihe, 2008). In particular, concerns have been raised about whether partnering managers have the adequate and the appropriate management skills and competencies to manage in networked or inter-sectoral settings involving such huge investments. For example, a recent report in the UK has drawn attention to skill deficiency for government managers to manage PFI projects. It is estimated that around 860 PFI projects, worth £239 billion were made over the past 20 years in the UK (Parker, 2012). It is found that these managers lack adequate skills and direct experiences in procurement, negotiation, design and construction areas to manage such projects (Parker, 2012).

The managerial aspect of a PPP, and particularly during the implementation phase of development, is the most problematic type of management due to the complicated and uncertain organisational settings that PPPs operate within (Bovaird, 2004; Vining \& Boardam, 2008). The sophisticated management competency and expertise 
required to manage this type of networked, multi-relational and hybridised organisations add more challenges to the management and application of PPPs. This research is intended to provide deeper insights and understanding of the micro-level competency management aspects or the soft skills of managing PPP projects, and whether any other skill requirement is evident in managing PPPs.

Following a qualitative research approach and using interviews, this research has investigated two case study organizations in Jordan, between 2009 and 2010. A total of 21 PPP managers (public and private) have participated in this study. Content thematic analysis was used to analyse the data collected.

\section{Literature on PPP Management Competency}

The precise definition of what PPP entails is difficult to achieve for several reasons. It could be because the term has involved different forms and partners and has been interchangeably used with other forms of public service delivery. The term has also lacked an agreed-upon vocabulary for describing different cooperative efforts and has been addressed from multidisciplinary backgrounds. It could also be because the precise boundaries of the PPP field are still emerging (see for this, Hodge \& Greve, 2007; Neal, 2010; Schaeffer \& Loveridge, 2002; Siemiatycki, 2010; Vining \& Boardam, 2008). Nevertheless, a PPP can be broadly defined as a partnering process between two or more public and private sector organisations, to produce and/or deliver a public good or service that may not have been possible without this partnership arrangement.

The need for unique skills and competencies to effectively manage PPP arrangements is an issue of great importance, especially in organisational settings or environments that are described as highly sophisticated and uncertain. These arrangements are also described as under-organised, networked, multi-sectoral and multi-organisational systems that exclusively need unique management skills and competencies. Therefore, it can be argued that one of the prerequisites for the successful implementation of PPP is the availability of specialized management expertise and skills to effectively manage in a PPP settings.

Notwithstanding the significance of identifying what can be considered a 'unique' or 'special' PPP management skills, little empirical research has been done on what constitutes the basis for management expertise and competence in partnerships and alliances. Acar et al. (2007) for example, have questioned the extent to which the set of skills are necessary for effectively manage in network settings and in what combinations, and, whether any other sets of skills are instrumental in the management of partnerships? To answer these questions, Acar and his colleagues suggested that empirical research is needed to explore the precise set of skills, values and attitudes that managers display in such settings. Also, Bach and Whitehill (2008) and Noble and Jones (2006) agreed that further research is needed to explore the requirements of the effective PPP management practices, the kind of skills, experiences, and knowhow the staff need, and learn new and different methods of managing in a cooperative inter-sectoral relationship settings. Jones and Noble (2008) also noted that managers "may need to change their managerial style and mindset to enable them to cope with a PPP's unique environment" (p. 113).

In the extant PPP literature related to the competency aspects of managing PPPs, it is reported that PPP managers from both sides of the partnership are often lacking managerial and directing skills, experience and knowledge in managing such 'hybrid' organisation forms (see for example, Brown, O'Toole et al., 2004; Hartman, Hofman et al., 1999; Malmborg, 2003). It is suggested that managerial techniques and skills designed for the traditional command-and-control hierarchical administration need to be modified to succeed in collaborative and networked partnership settings (Acar et al., 2007).

The need for directing and leadership skills in managing PPPs was particularly emphasised by several PPP scholars. Hartman et al. (1999), for example, suggested that collaborative leadership is a necessary ingredient for partnerships. For Hartman, et al. (1999), collaborative leaders are those "individuals and social entities who have the credibility and entrepreneurial initiative to bring the right individuals, organisations and constituents together constructively to create vision, solve problems and reach agreements" (p. 257).

Using Edwards' "competing value approach" as an analytical framework for their study, Acar et al. (2007) agreed that this framework "posits that public and nonprofits managers, confronted by a series of competing values or demands pulling them in many directions concurrently, must play multiple roles and have multiple sets of skills" (p. 34). The result of the interplay of two dimensions (flexibility versus control and internal versus external) that Acar et al, (2007) suggested, yields four distinct sets of management skills that PPP managers need, these being: boundary-spanning; human relations; coordinating; and directing skills. The researchers also identified nine discrete categories of management competencies that are needed to effectively manage partnerships. The nine skills (9Cs) (sorted in order of importance) are: communication skills; connectivity and connective skills; collaborative attitude and skills; convening and coordinating skills; congeniality and collegiality; caring for and championing clients; coaching and consulting skills; creativity; and credibility skills 
(Acar, et al., 2007).

The importance of effective communication and coordination skills for partner managers was particularly emphasized by few other PPP researchers. For example, one important lesson learnt from the successful partnership between the U.S. Department of Health and Human Services and the Robert Wood Johnson Foundation (RWJF) was that partners could quickly address and manage communication challenges by jointly creating a national program office to ensure that all parties were always in the communication loop (Knickman \& Stone, 2007).

Very little research is found in the extant PPP management literature providing details of the management competency requirements to effectively manage in a PPP environment. Skill deficiency in managing PPPs in theory and practice, then, represents a significant gap in the current understanding and management of PPPs (see Table 1). In the UK, for example, a report published in September, 2008, by the Public Account Committee found that many public sector managers did not have the "commercial" expertise to oversee multimillion pound projects over a long period (Read, 2008). In addressing the National Audit Office Annual Private Finance Conference in UK in July 2008, Edward Leigh (the influential chair of the Public Accounts Committee), among other speakers, raised concerns about the unavailability of the right number of staff with appropriate expertise to manage PFIs, given that private finance deals had been a feature of public sector procurement since the mid-1990s (Russel, 2008). Therefore, it is suggested that further research is required to examine the types of management expertise, skills, and leadership needed to effectively manage in a PPP settings. Two PPP projects in Jordan have been chosen to collect field data for this research.

Table 1. PPP management competency requirements identified in the PPP management literature

\begin{tabular}{lc}
\hline \multicolumn{1}{c}{ Findings } & PPP Researchers \\
\hline $\begin{array}{l}\text { Personal attributes and abilities } \\
\text { collaborative attitude }\end{array}$ & Acar et al, (2007) \\
Skills & \\
Directing and leadership skills (collaborative & Brown et. al (2004); Hartman et al. \\
leadership; coaching and consulting; caring & (1999); Malmborg (2003); Acar et al, \\
for and championing clients) & (2007); \\
Boundary-Spanning; & Acar et al, (2007); \\
Human Relations; & Hartman et al. (1999); \\
Coordinating and convening & Knickman \& Stone (2007) \\
Communication; & Acar et al, (2007); \\
Connectivity/Connective; & Knickman \& Stone (2007) \\
Congeniality And Collegiality; & \\
Creativity; And, & \\
Credibility & \\
Experience & \\
- & \\
Knowledge, training and qualification & - \\
-
\end{tabular}

\section{PPP Market and Research in Jordan}

Strategically, PPPs in Jordan are considered as a key component of the country's economic development strategy (El-Khatib, 2008). However, only recently PPPs were introduced to the Jordanian market. The first PPP project entered into the implementation stage in mid- 2003 was the Jordan Education Initiative (JEI). Institutionally, the legal and institutional frameworks have existed only since 2007, when the PPP policy was enacted. The legal and institutional frameworks for PPPs had not existed before 2000, when the Privatisation Law (which was only enacted in 2008) included some reference to PPPs to provide the legal framework for PPPs in Jordan. As part of 
the economic reform measures to mobilise private investments, Jordan officially launched its PPP Program in 2008, and assigned its implementation to the Executive Privatisation Commission (EPC) as the central agency tasked with the implementation of privatisation and PPP programmes in Jordan. According to the 2008 Privatisation Regulation, and with respect to the implementation of PPPs in particular, it is mandated that studies should be conducted to investigate the social, economic and environmental aspects of the proposed project, to effectively manage PPP projects (with no reference to the managerial-type issues, or the competency requirements). As such, the legal and institutional frameworks for PPPs in Jordan are still not yet well-developed and can be described as fragmented and immature.

On the application side, the government of Jordan (GoJ) is going ahead rapidly with using PPP arrangements and initiatives in both infrastructure and services sectors. Since the year 2000, GoJ has announced more than 35 initiatives that use two or more PPP forms and arrangements. Jordan expects overall infrastructure spending averages to be around \$US 750 million to \$US 1.1 billion a year through to 2015 (El-Khatib, 2008). One of the biggest ever investment in Jordan will be the Red Sea Canal (RSC). The project, which is currently under study, will connect the Red Sea (south) to the Dead Sea (north) and will enable Jordan to produce hydroelectric power and satisfy its water requirement needs). This project, using a PPP arrangement that could cost as much as US\$ 3 billion to complete.

Using the PPP market maturity curve suggested by Siemiatycki (2010), Jordan's experience in PPPs, as compared to its own economy, can be rated moderately high in activity and low in institutional and legal framework sophistication (see Figure 1). According to Siemiatycki (2010), the PPP market in the UK is the most active worldwide. It has the most developed and sophisticated institutional, legal, regulatory and business structure to support the implementation of PPPs.

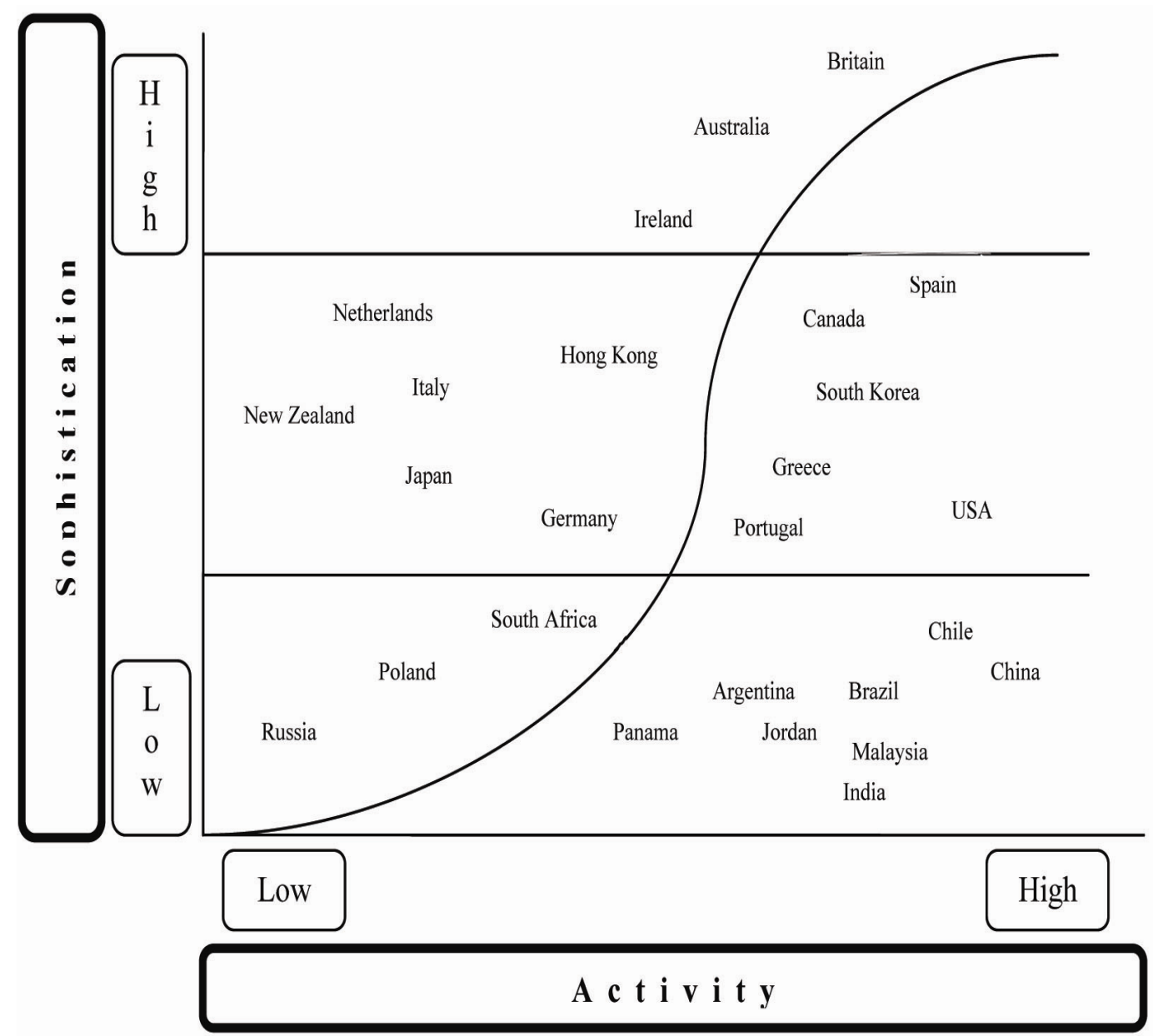

Figure 1. PPP Market Maturity Curve

Source: Siemiatycki (2010) 


\section{Research Method and Approach}

Due to the limited literature on the subject under study, this research was conducted following qualitative research approach, using interviews. The study is based on information collected from two PPP infrastructure projects in Jordan used as case studies, namely, Queen Alia International Airport (QAIA) and Samra Waste Water Treatment Plant (SWWTP). Managers from different partnering organisations in each PPP project, representing all senior level management employee (A total of 24 managers) within the two case study organizations, were targeted to participate in this study. A total of 21 interviews were conducted in the two case studies (10 and 11 interviews were conducted in Studies One and Two respectively). The remaining 3 potential participants were unavailable during the period of data collection. Interviews were conducted at the organisational workplace in Jordan during September 2009 and January 2010. Content thematic analysis was undertaken to analyse the data collected with the aid of Leximancer software, particularly for data management and organization purposes.

The selection of the case studies was based on the theoretical sampling technique and other criteria such as access, availability and convenience. In essence, case studies "are chosen because it is believed that understanding them will lead to deeper understanding, or better theorising, about a larger collection of cases (see, Stake, 1998). Further, the two cases were in different stages of their implementation phase (e.g. internally heterogeneous). The first (QAIA) had started the construction stage and the second (SWWTP) had completed construction and started the operation stage when data collection was undertaken. Furthermore, the selected cases involve huge investment and are considered to be 'critical' to a small economy such as Jordan.

In approaching case study organizations, the strategy of sequential design (case studies follow one another) and prospective design (tracking changes forward over a certain period during the data collection and analysis) were employed. An in-depth, open-ended and semi-structured interview techniques were utilised. Additionally, information was collected from media, news releases and websites to triangulate the interview data.

It is acknowledged that this research addresses issues relating to the management of the implementation phase of PPP infrastructure projects in the Jordanian context. First, it is directed towards those PPPs which have already been established (e.g. the stage when the PPP contract has been signed and the project construction process has commenced or when the construction process has been completed and the delivery of the service has started). Therefore, this research does not focus on the policy or politics of establishing and developing a PPP arrangement prior to the implementation phase. Second, the research is delimited by the limited number of cases selected for the current research that was determined by the availability of PPP projects that have entered at least one of the two stages of the implementation phase to meet the objectives of this study.

\section{Case Study Organisations}

Follows, is an overview of the selected PPP projects for this study and details of the partnership arrangements for each.

\subsection{Study One: Queen Alia International Airport (QAIA)}

The expansion of the QAIA was originally planned to meet increasing demands and to handle projected traffic volumes of the airport in Jordan, and at the same time to enhance and develop its position as a regional hub to serve the increasing demands on the airport regionally. The project was initiated to introduce private sector finance and technical know-how to one of the most significant service sectors of the Jordanian economy.

The project agreement included that the construction of the new terminal be performed in two main phases. In the first phase, the expansion works was planned to provide a total capacity for up to 5.5 million annual passengers (MAP), over the capacity of the existing airport (which is $4.77 \mathrm{MAP}$ ), and was planned to be completed by the first quarter of 2011. The second phase, which is planned to be completed and fully operational in the first quarter of 2012, includes expansion for a capacity of up to 12 MAP, and will only start based on the traffic growth achieved on completion of the first phase of the project.

The QAIA project uses the BOT (build, operate and transfer) form of PPPs for 25 years. The estimated cost of the project is US\$ 700 million (This was increased later to US\$750 to facilitate expansion and improvement of the design). Following a competitive bidding process, the Aerports de Paris Consortium was announced as the winning bidder for this project in April 2007. Seven months later, this consortium formed a private company, named the Airport International Group (AIG), to manage and operate the project. The AIG is responsible for the maintenance and rehabilitation of the existing airport landside and airside facilities. It is also responsible for the design, engineering, procurement and rehabilitation of the new passenger terminal. The Aerport de Paris (a member of the AIG consortium) takes the role of day-to-day operation and management of the QAIA project. Likewise, the Program Management Unit (PMU), was given the role of managing the project, representing the 
Ministry of Transport (MoT) as public partners.

\subsection{Study Two: Samra Waste Water Treatment Plant (SWWTP)}

There is a significant shortage in water supply in almost all Middle East and North Africa (MENA) countries. It is well known that Jordan, in particular, suffers from a severe water scarcity problem, with an increasing demand for water resulting from escalating population growth and economic development. The SWWTP was also instigated because of the problem caused by the odour, lagoons and waste stabilization bonds that stemmed from the untreated water in the Samra Valley (PMU, 2009). With a budget of US\$169 million, the SWWTP was originally planned to provide significant quantities of irrigation water to farmers in the Jordan Valley and thus free the fresh water resources of the Valley for domestic uses in the Amman and Balqa regions. The plant was designed to serve approximately two million residents in Amman and Zarqa, the two major cities in Jordan.

Under a 25-year agreement, using BOT form of PPPs, the SWWTP involved the design, construction and operation of new wastewater treatment facilities, and at the same time, modification and expansion of the Ain Ghazal pre-treatment facility. It also involved the maintenance of the main pipeline which collects wastewater from Amman, the capital city, and the surrounding suburbs. Together, these improvements have replaced the overloaded and inadequate old waste stabilization pond treatment system.

By the end of 2003, the SWWTP was announced by signing the project agreements between the Ministry of Water and Irrigation (MWI) and Samra Procurement and Construction Company, representing the private sector partners. The construction process in the site started in February 2004. In August 2008, the project was officially launched after about five years of construction.

The SWWTP is considered the biggest environmental project of its nature and volume in Jordan, and the first PPP for wastewater treatment facility in the Middle East. It is also the first wastewater treatment facility in the region to have used a combination of public and private partners from local, regional and international organisations. Based on the project's design and implementation, USAID anticipated that this project will serve as a model for future water investments in the region.

Since its completion in 2008, the facility has treated more than 56 million cubic meters (MCM) of wastewater and substantially increased water availability for use in agriculture in the Amman and Zarqa regions (PMU, 2010). For farmers located in the Jordan Valley who use the King Talal Dam water to irrigate their farms, the improvement of the water quality means less maintenance for their irrigation system (e.g. clogging of emitters) and so higher revenues (PMU, 2009).

To construct and operate the plant, Infilco Degremount and Morgantti which represented the private partner, had formed a consortium joint venture in 2003. Together, they then established the Samra Procurement and Construction Company- SPC (or Samra Plant Consortium) to take the role of the day-to-day construction, operation and management processes of the project.

On the public side of the partnership, a Program Management Unit (PMU) was originally established by the MWI to serve as a management tool to assist the ministry, the Water Authority of Jordan (WAJ) and the Jordan Valley Authority (JVA) in various strategic activities; (The WAJ and JVA are public sector establishments that are structurally and functionally related to the MWI). After the SWWTP came into existence, the PMU was assigned the role of overseeing and managing this project, representing the public partner, despite the fact that the unit was involved in the project from the outset. The PMU had participated in preparing the feasibility studies of the project and currently assisting the MWI, WAJ and JVA in the preparation and follow up of the project's agreement, and in negotiating with the strategic partners and the sub-contractors.

Although the PPP arrangement of the QAIA and the SWWTP projects involve contributions and participation from several organisations, few of them are directly involved in the managerial aspects of these projects. The PMU which represents the public sector partner and the Aerport de Paris which represents the private sector partner in the QAIA are directly responsible for the day-to-day operation and management of the project. Likewise, the PMU (and its relationship with the MWI), and the SPC (and its relationship with Infilco-Degremont and Morganti) are also the bodies directly involved in the management aspects of the SWWTP projects. Because this research is primarily directed towards the management competency aspects of the PPP projects during the course of their implementation, researching these four 'managerial entities' was the focus of this study.

\section{Research Findings}

The management expertise and competency requirements for the effective management of PPPs that emerged from the data collected were organised under four main categories, namely: personal qualities and attributes; 
skills; experiences; and, knowledge, training and qualifications. Table 2 provides a summary of the key findings for this study and highlights the newly emerging themes and those that reinforced earlier findings in the literature on the PPP management competency requirements. A coding system for the study informants was used to relate the participants to their context (the project in which they work and the organisation's sector). For example, the code $S 2.5 / P c$ represents participant number five, in study two (SWWTP), representing the public sector partner $(P c)$. The same coding applies to the rest of the study participants. $(\mathrm{Pt})$ describes the public sector partner.

Table 2. Study Key findings

\begin{tabular}{|c|c|}
\hline Key Findings/Themes & Relation to Literature \\
\hline \multicolumn{2}{|l|}{ Personal attributes and abilities } \\
\hline $\begin{array}{l}\text { Adaptability and flexibility; and, patience and self-motivation are personal } \\
\text { qualities and abilities were important for the PPP managers }\end{array}$ & Newly emerging \\
\hline \multicolumn{2}{|l|}{ Skills } \\
\hline $\begin{array}{l}\text { A set of skills were important to effectively manage in a PPP setting. These were: } \\
\text { social and interpersonal skills; 'scoping in/out' ability; conceptual skills; project } \\
\text { management skills; and, communication and coordination skills }\end{array}$ & $\begin{array}{c}\text { Reinforced / } \\
\text { Newly emerging }\end{array}$ \\
\hline \multicolumn{2}{|l|}{ Experience } \\
\hline $\begin{array}{l}\text { PPP managers should have sufficient technical and project management } \\
\text { experience, as well as experience in negotiation and arbitration }\end{array}$ & Newly emerging \\
\hline \multicolumn{2}{|l|}{ Knowledge, training and qualification } \\
\hline $\begin{array}{l}\text { PPP managers should be knowledgeable and qualified to manage the } \\
\text { construction, operational and the financial aspects of the PPP project. They } \\
\text { should also be familiar with, and use specialized programming and scheduling } \\
\text { techniques }\end{array}$ & Newly emerging \\
\hline
\end{tabular}

\subsection{The Personal Attributes and Abilities in Managing PPP Projects}

This study has revealed a number of personal qualities and abilities suggested by the interviewees that should be available to the person who takes the role of managing PPP projects. Although less cited by the public partner managers across the two cases, these attributes and abilities were viewed by the private partner managers as closely related to effective PPP management.

The ability to cope with, and adapt to different changes in the other partner during the course of the partnership, was one of the most important attributes that should be available to a PPP manager (cited by $63 \%$ of the interviewees). One of the interviewees mentioned: "As PPPs generally space from 10 to 30 years, the governing parties/blocks will undoubtedly change several times over the course of the partnership. So, it is essential that managers have the ability to adapt to shifts in policies and representation" $(\mathrm{S} 1.10 / \mathrm{Pt})$.

Further, the interviewees suggested that PPP managers should be flexible to adjust their management style to suit the new working environment (58\% of citations). One interviewee commented: "It is [about] adjusting to a certain management style that mostly fits into each new project / country, and changing the ways of thinking and doing things" (S2.10/Pt).

Finally, being patient and self-motivated were the third most important traits that PPP managers are perceived to need (with $53 \%$ of citations). PPP managers agreed that having these traits enabled them to accommodate themselves to deal with desperate situations where the ups and downs were usually everyday happenings in managing PPP-type projects. One interviewee noted: "It is not easy to take things a bit easily in a working environment that is highly stressful and sometimes devastating. But, a PPP manager should take things patiently and steadily. After all, I look outside this window and can see the factory is now up and running. So, why worry?" (S2.6/Pt).

\subsection{The Skills Required in Managing PPPs}

Across the two case projects, the skills that were cited by the interviewees as needed to effectively manage a PPP project were (in descending order of importance): social and interpersonal skills; scoping in/out ability; 
conceptual skills; project management skills; and, inter-organizational communication and coordination skills.

As mentioned by the interviewees, having social and interpersonal skills such as arbitration and negotiation skills were important requirement in the first place for more effective PPP management (with $58 \%$ citation). On the importance of having these skills, one interviewee commented: "We spend most of our time talking to people inside/outside this project. So, having social and communication skills are all highly important in our internal and external relationships. Negotiation and arbitration skills are also highly needed, particularly in our dealings with our partners" (S1.3/Pc).

For the managers to be successful in managing their PPP organisations, the ability to 'scope in and out' was the second important personal attribute that PPP managers must have (cited by 53\% of interviewees). According to the interviewees, this meant that managers should be deeply involved in the daily routines of the work, and at the same time, be able to see the whole picture from a broader angle and a longer distance from time to time. One interviewee confirmed: "While we [PPP managers] are heavily involved in our daily routines, we exercise sort of 'zooming in/out' to make sure whether our actions are taking us the right direction" (S2.9/Pc).

Equally important, the interviewees insisted that the PPP managers should also have good conceptual skills to assist them finding solutions to the problems they might face in their relationships with their partners, and to be able to generate new avenues for solution and think visionary outside the box (53\% of citations). Also, equally important, having project management skills was a necessity in managing PPPs ( $53 \%$ frequency of mentions).

To effectively manage in a PPP settings, the ability to manage inter-organizational relationships (IORs) between partner managers and communication and coordination skills were also other important skills that the PPP managers necessitate (cited by $48 \%$ of the interviewees). For the PPP mangers, these skills helped in keeping the other partner fully engaged in the partnership and assisted in addressing and sorting out the institutional differences between partners timely and effectively. One interviewee commented: "As you see, our offices are just few metres from theirs. We meet in the corridors, in the lifts, on the stairs, even outside work! We chat, ask questions, get advice, arrange things. It's an everyday stuff. Though, we have official meetings whenever there is a matter of concern like a 'big variation of money order"' (S1.7/Pc).

Reference to the importance of having both social and technical sides of project management skills seemed to be shared amongst the majority of the PPP project managers.

\subsection{The Experiential Background of the PPP Managers}

The interviewees perceived that PPP managers should have an outstanding technical experience in the first place (with $63 \%$ of citations), project management experience in the second place (with $53 \%$ of citations), and lastly, negotiation and arbitration experience (with $24 \%$ of citations). Two interviewees explained how important these experiences were to the PPP managers: "We had situations when we were so desperate in finding the right people from the local market who have had previous experience in working in similar projects. We ended up recruiting from Egypt and India. Well, this is not bad. You see not all players in Real Madrid are Spanish" (S2.7/Pt): "Any manager working in this project [the SWWTP] has to 'get his fingers into the water' [to appreciate and value the importance of water; to have experience in the water industry]. Business-sound experience in negotiation and arbitration is also a necessity for our work" (S2.3/Pc).

Therefore, the type of experience that was most needed in managing PPPs was mainly related to technical and social communication experiential aspects. Having previous technical and project management experience, as well as experience in negotiation and arbitration were such examples.

In terms of the previous and current experience that the study informants have in the respective projects, across the two cases of the public and private partner managers, it is noted that all participants had only minimal prior experience in managing similar projects (an average of 7.6 years), as well as in the current management of their projects (an average of 4.1 years), (see Table 3). It can also be noted that public sector managers have had a fewer number of years of experience (both previous and in-project) compared to their private sector counterparts (5.6 and 4.2 versus 10.4 and 7.2 respectively). Further, the experience gained by participants from both sectors who are involved in the management of the SWWTP is notably more than those who are involved in managing the QAIA project. 
Table 3. Years of experience of study informants

\begin{tabular}{lcccc}
\hline & \multicolumn{2}{c}{$\begin{array}{c}\text { Years of Experience (Public } \\
\text { Partner Managers) } \\
\text { Previous }\end{array}$} & $\begin{array}{c}\text { Current } \\
\text { (In-Project) }\end{array}$ & \multicolumn{2}{c}{$\begin{array}{c}\text { Years of Experience (Private } \\
\text { Partner Managers) } \\
\text { Previous }\end{array}$} & $\begin{array}{c}\text { Current } \\
\text { (In-Project) }\end{array}$ \\
\hline QAIA & 5.6 & 1.8 & 9 & 3.3 \\
SWWTP & 5.6 & 4.2 & 10.4 & 7.2 \\
average & 5.6 & 3.0 & 9.7 & 5.25 \\
total average & $>$ & previous experience: 7.6 years & & \\
& $>$ & in-project experience: 4.1 years \\
\hline
\end{tabular}

\subsection{PPP Knowledge, Training and Qualification Requirements}

It was consistently agreed by the interviewees, across the two case studies that PPP managers should: be well-trained and qualified to manage business/public-type projects (with $76 \%$ of citations); have extensive knowledge in managing the project's construction and operation (with $71 \%$ of citations); be qualified to handle the financial and cost management aspects of the project (with $58 \%$ of citations); and, be familiar with, and able to use programming and scheduling techniques (with $43 \%$ of citations). One manager explained: "Not only we have few PPP-experienced people, but we also don't have at all employees who have qualifications in managing PPP projects, which we desperately need. Admittedly, to be able to manage this project, managers should be Project Management Professional (PMP) certified, which I personally do not have" (S1.7/Pc).

Knowledge in construction and operation processes of the project was another important ingredient of the PPP management competency. Adding to this, knowledge in other managerial and technical systems, which were directly related to the workplace requirements/settings was also important. Further, in order to effectively and efficiently manage PPP projects, the interviewees insisted that PPP managers must have extensive knowledge in the financial aspects of the project, as well as monitoring and scheduling techniques and methods. Two interviewees explained: "We recruited people from Greece to construct the Domes that needed highly specialised labour force. Also, knowledge in Quality Assurance (QA), Quality Control (QC) and Health, Safety and Environment (HSE) are of great importance in the management of 'this' project" (S1.9/Pt); "How could you run this project without having sufficient knowledge in the systems and techniques like CPM [Critical Path Methods]?" (S1.1/Pc).

Other favourable types of knowledge and qualifications that the PPP managers should have, mentioned less frequently by the interviewees, were: knowledge in the policies and practices adopted by the partner; computer literacy; and, legal and contracting knowledge.

\section{Discussion}

In the PPP literature, scholars were in agreement that PPP managers should possess necessary special skills and expertise as a requirement to effectively manage PPP-type projects. Concurrently, researchers questioned whether the skills in traditional command-and-control structures fit into a multi-organisational partnership environment, and whether any other sets of skills are instrumental in the management of PPPs. In the meantime, a few researchers have attempted to identify a number of skills that they considered crucial in managing PPPs. Despite these few attempts to give prescriptions of what 'should be' the 'right' or 'special' skills required to manage PPP-type organisations, it can be noted that little empirical research has been initiated to investigate whether these 'special' skills are what exactly required to effectively manage in a PPP setting in reality (see for example, Acar et. al., 2007).

The type of personal qualities, experience, skills and knowledge that this research has identified was organized under two main categories: (1) the personal qualities, attributes and abilities that the individual PPP managers themselves have to bring to their PPP organisations for more effective management; and (2) the skills, knowledge and training that the PPP organisation can provide to the PPP managers to improve their performance in managing their organisations (see Figure 2). 


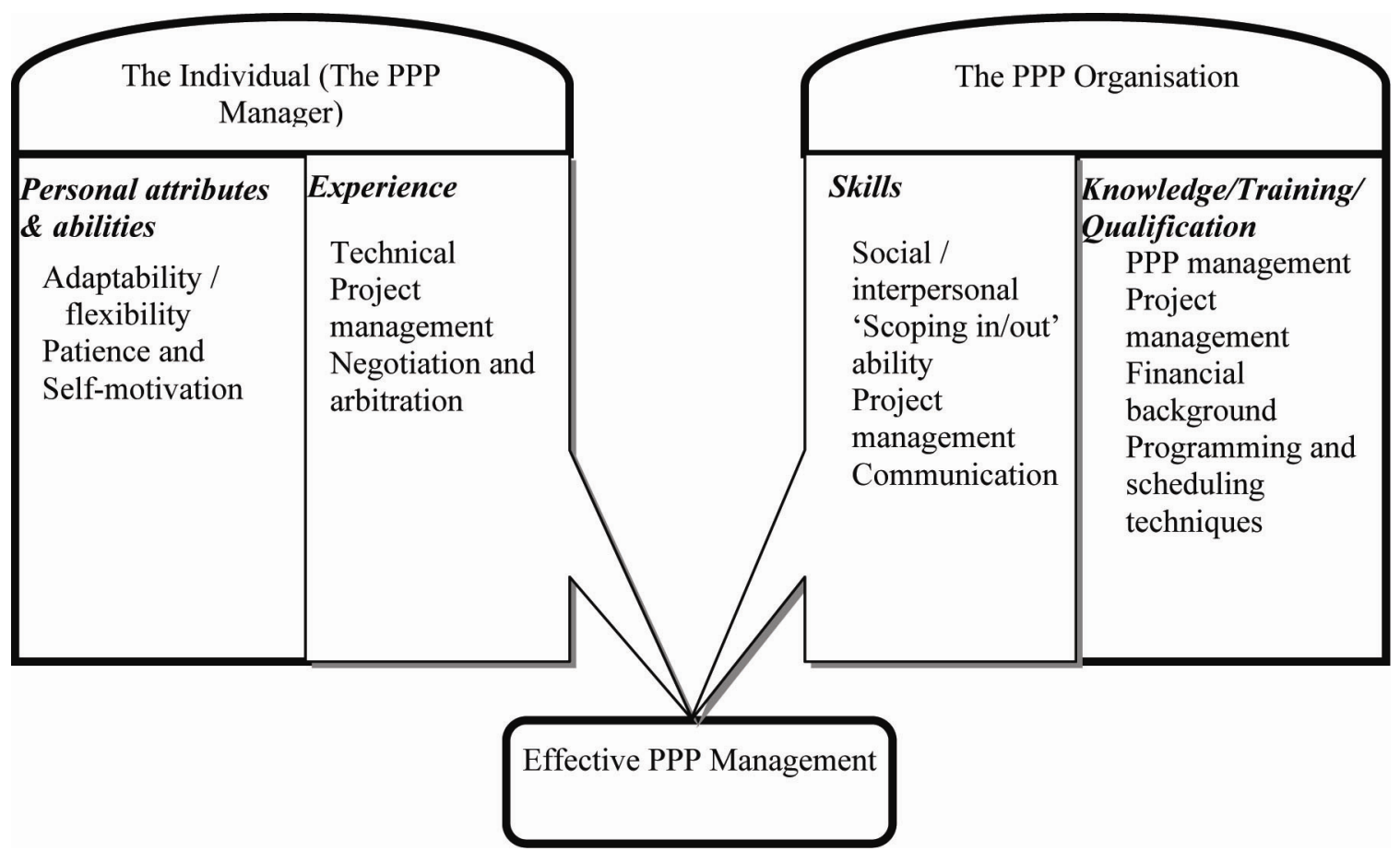

Figure 2. Individual and organisational PPP management competency

In essence, this research has provided a wide-ranging account of the type of competency and expertise required for the effective management of the PPPs that was not available in the PPP literature. It has responded to Bach and Whitehill's (2008) and Noble and Jones' (2006) call to explore the management expertise and competence needed in multi-organisational settings. Thus, this research adds to the 9Cs that Acar et. al. (2007) identified, as well as extending the PPP literature in identifying the kinds of personal and professional competencies that managers need to effectively manage in a PPP environment (see Table 4). In particular, this research reconfirmed the importance of communication, coordination and social and interpersonal skills (human relation skills in Acar's et al., 2007 model) that PPP managers should have to effectively manage their projects. Further, the importance of having directing skills (e.g. leadership skills) that was highlighted by some PPP researchers (e.g. Brown et al., 2004; Hartman et al., 1999; and, Malmborg, 2003) was also emphasised in this study. The interviewees stressed the importance to keep focused on the broader vision of the PPP project in the course of routine daily activities. The availability of this ability to the PPP managers has greatly assisted them directing their employees and devoting PPP resources toward the final goal of their PPP projects.

Table 4. PPP management competency requirements identified in the PPP management literature and in this research

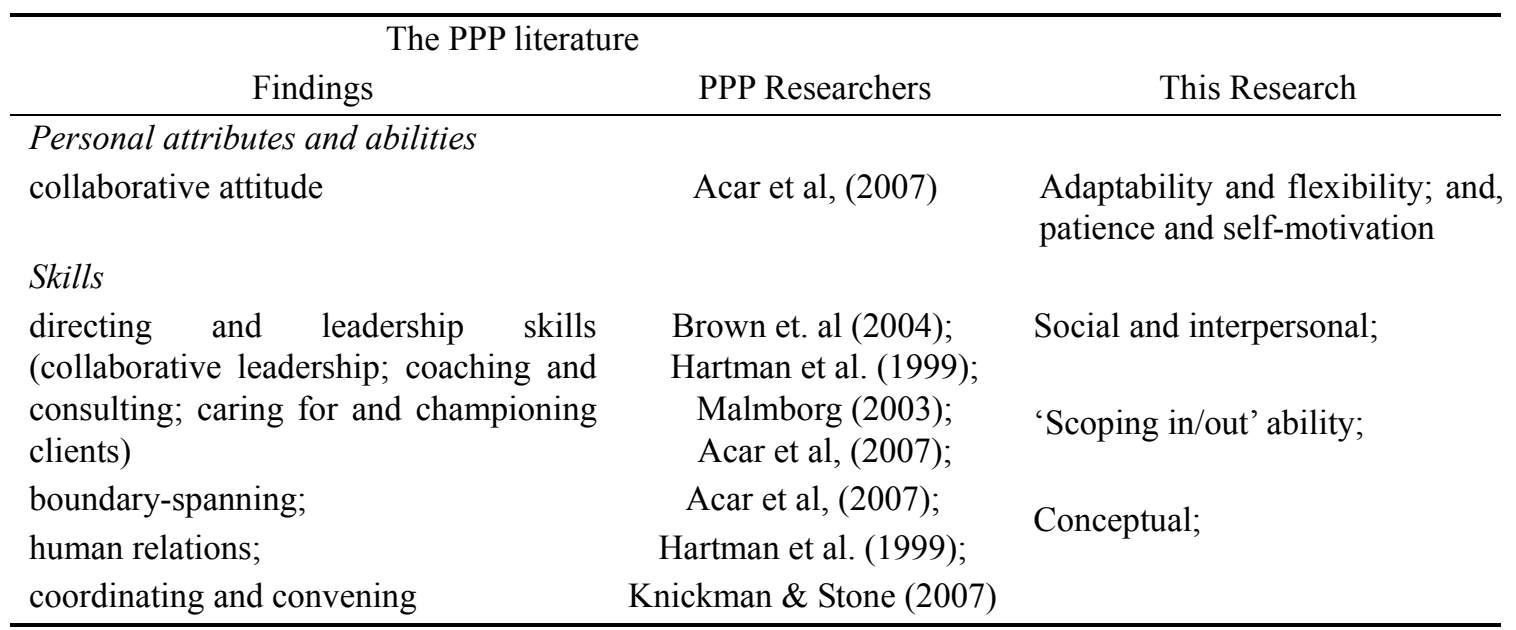




\begin{tabular}{|c|c|c|}
\hline $\begin{array}{l}\text { communication; } \\
\text { connectivity/connective; }\end{array}$ & $\begin{array}{c}\text { Acar et al, (2007); } \\
\text { Knickman \& Stone (2007) }\end{array}$ & Project management; \\
\hline $\begin{array}{l}\text { congeniality and collegiality; } \\
\text { creativity; and, } \\
\text { credibility }\end{array}$ & & $\begin{array}{l}\text { Inter-organizational } \\
\text { communication and coordination } \\
\text { skills }\end{array}$ \\
\hline \multicolumn{3}{|l|}{ Experience } \\
\hline- & - & $\begin{array}{l}\text { Sufficient technical and project } \\
\text { management experience; and, } \\
\text { experience in negotiation and } \\
\text { arbitration }\end{array}$ \\
\hline \multicolumn{3}{|c|}{ Knowledge, training and qualification } \\
\hline \multirow[t]{2}{*}{-} & - & $\begin{array}{l}\text { Specialized knowledge and } \\
\text { qualification to manage the } \\
\text { construction, operational and } \\
\text { the financial aspects of the PPP } \\
\text { project. }\end{array}$ \\
\hline & & $\begin{array}{l}\text { Knowledge and training in } \\
\text { specialized programming and } \\
\text { scheduling techniques }\end{array}$ \\
\hline
\end{tabular}

Managing in multi-sectoral, multi-relational and/or multilateral-type of organisational settings was acknowledged by this study, as well as in the PPP literature as a different form of management (see for example, Keast at al., 2004; Teisman and Klijn, 2002; Lasker, Weiss and Miller, 2001; Pessoa, 2008). It requires a shift in roles, plus a way of viewing and doing things, and being flexible to effectively respond to the unexpected changes in the environment that are more common occurrences in managing PPPs than occurs in traditional unilateral-owned organisations.

In the PPP literature, very little research was found to provide details about the type of prior knowledge/experience needed to effectively manage PPP projects, in response to Bach and Whitehill (2008) and Noble and Jones' (2006) call to explore the requirements for the kinds of experiences needed for more effective PPP management. In this research, prior experience and knowledge in managing similar PPP projects was found to be one of the important factors that improved the abilities of the PPP managers to effectively manage their PPPs. However, for the private sector managers, prior experience, although important, was not an issue of a 'big' concern as most of the managers have already had the opportunity to work on similar regional and international PPP projects. The public partner managers were also aware of the importance of having prior PPP management experience and compensated for the lack of experience for some of the managers by providing them with training and induction programs, locally and internationally.

Despite that private sector partner managers particularly have had prior experience in managing previous PPP projects, and the training that public sector partner managers have been provided with during the course of the project, it is suggested that they both have not had sufficient past experience to manage in a PPP setting (an overall average of 7.6 years of previous and 4.1 years in-project experience; see Table 3).

It is acknowledged that PPPs have been newly introduced in Jordan as well as internationally, and more time will be required to gain experience in managing PPP-type projects. Also, that public sector managers have had a fewer number of years of experience compared to their private sector counterparts can be explained by the fact that private sector participants had more managerial exposure to similar experiences in similar projects internationally than their public sector counterparts. Further, the experience gained by the SWWTP managers was notably more than those of QAIA, could be because the SWWTP had started the construction stage earlier (in 2004) and entered the operation stage of its lifecycle earlier too (in early 2009). Therefore, managers have had the opportunity to gain more experience than their counterpart managers of the QAIA, which has only recently started the construction stage (in 2009).

Overall, this research identified, in detail, what can be considered as a personal attribute, experience, skill and/or knowledge that is important for the effective management of a PPP organisation. Simultaneously, it established divisions/differences between qualities and abilities that PPP managers should personally have before being engaged/involved in the management activities of the PPP project, and the skills and knowledge that the PPP 
organisation can provide to the PPP managers to assist them in building their capacity for more efficient and effective management performance.

\section{Research Implications}

The wide-ranging account of the type and nature of management competency requirements to manage effectively in a PPP environment that this research has identified, and modelling these competencies into organisation-related/individual manager-related, will assist in better understanding of these competencies and the way of viewing and studying them. It also adds to our understanding of the requirements for effective management in a PPP environment. For practitioners and managers, the insights that this research has provided into the management of PPPs will assist them in managing their PPP projects more effectively. For managers and policy makers alike, expanding knowledge on the management of PPPs will greatly improve the chances for their success, and consequently prevent loss of huge investments in the PPP market worldwide, particularly in the developing economies such as Jordan where resources are scarce. This research will also help to improve understanding of PPP managers of how well partnerships are (and should be) effectively managed in a way that reflects positively on their management performance. Further, the findings of this research will assist PPP managers on the kind of personal qualities, skills, experiences, knowledge, training and qualification that they should possess so that they are able to manage in multi-sectoral, multi-relational, multi-cultural and/or multilateral-type organisational settings.

This research has important policy implications for policy makers about the anticipated challenges in the management competency that PPPs could face during their implementation and to improve their knowledge in making more rational human resource policies and decisions before the commencement of the PPP project. The lessons learnt from the PPP management skills of the two case study organisations in Jordan will have important implications for creating more effective PPPs in other contexts regionally and internationally.

\section{Conclusions}

Because PPP arrangements usually involve huge investments, PPP policy makers, partners, managers and researchers have genuine concerns about the outcomes of these partnership arrangements. Also, because PPP have been recently introduced by governments as an option to produce and deliver goods and services to the public, there is little knowledge and experience in establishing and managing these types of hybridised projects.

An exploratory case study approach, by its very nature is bound by not being fully generalisable. There are limitations about the extent to which results from this study can be generalised beyond the two case organisations selected for investigation in this research (e.g. external validity). However, case studies are not designed to provide a basis for making statistically valid generalisation beyond them; they do not strive for this type of external validity. They are designed to help understand a phenomenon and/or develop, refine and test theories. They do this using the logic of replication (see, Eriksson \& Kovalainen, 2008). Hence, the two case study organisations were chosen as unique cases and represented two different stages of a PPP development lifecycle (the construction and delivery stages). Therefore, they were internally heterogeneous (to obtain richer information) and externally homogeneous (to provide basis for consistent comparison). Hence, the organisations chosen for this research may have represented other similar infrastructure projects in Jordan and MENA countries, as the challenges and issues surrounding the management of these PPPs in the implementation phase of development are likely to have very similar attributes.

This research utilised the perceptions of the PPP managers interviewed as a main determinant for exploring the effectiveness of the case study organisations. It might have been valuable to seek the perceptions of other people involved in the partnership process such as other employees, 'parent' and 'participant' partner managers. However, targeting PPP managers was based on the assumption that they are the most knowledgeable subject of inquiry. Further, because a PPP arrangement can be described as a multi-disciplinary research area, a coherent and/or agreed upon effectiveness measurement framework to precisely assess the extent to which a PPP arrangement is effectively managed, or broadly achieve its objectives, is not yet available in the extant literature and needs development.

Future research needs to consider limitations and delimitations of this study. In particular, future research could use other case studies from different geographic and socio-economic locations regionally and internationally. An extension to this, would be to use PPP case studies from other industry settings such as education, health, information technology or energy, in Jordan, the MENA region and/or worldwide. Additionally, further research is required to explore whether there are any other management competency requirements (other than those identified by this research) that closely related to the effective management of PPPs. Further, whether these competencies are different or similar, (as the case might be), to what is required in the traditional 
command-and-control management structures, needs further research.

\section{References}

Acar M., Guo, C., \& Saxton, G. (2007). Managing Effectively in a Network World. Public Manager, 36(2), 33-39.

Bach, V., \& Whitehill, M. (2008). The Profit Factor: How corporate culture affects a joint venture. Strategic Change, 17, 115-132. http://dx.doi.org/10.1002/jsc.820

Bovaird, T. (2004). Public-Private Partnerships: From contested concepts to prevalent practices. International Review of Administrative Sciences, 70(2), 331-334. http://dx.doi.org/10.1177/0020852304044250

Brown, M., O'Toole, L., \& Brudney, J. (2004). Implementing Information Technology in Government: An Empirical Assessment of the Role of Local Partnerships. Health Promotion International, 19(1), 5-15.

El-Khatib, A. (2008). Privatisation and PPP in Jordan. Paper presented at the second Jordan capital market, London.

Eriksson, P., \& Kovalainen, A. (2008). Qualitative methods in business research. Thousand Oaks: Sage Publications.

Grossman, S. (2010). Reconceptualizing the Public Management and Performance of Business Improvement Districts. Public Performance \& Management Review, 33(3), 361-394. http://dx.doi.org/10.2753/PMR1530-9576330304

Hartman, C., Hofman, P., \& Stafford, E. (1999). Partnerships: A Path to Sustainability. Business Strategy and the Environment, 8, 255-266. http://dx.doi.org/10.1002/(SICI)1099-0836(199909/10)8:5<255::AID-BSE214>3.0.CO;2-O

Hodge, G., \& Greve, C. (2007). Public-Private Partnerships: An International Performance Review. Public Administration Review, 67(3), 545-558. http://dx.doi.org/10.1111/j.1540-6210.2007.00736.x

Jones, R., \& Noble, N. (2008). Managing the Implementation of the Public-Private Partnerships. Public Money \& Management, 28(2), 109-114. http://dx.doi.org/10.1111/j.1467-9302.2008.00629.x

Keast, R., Mandell, M., Brown, K., \& Woolcock, G. (2004). Network structures: Working differently and changing expectations. Public Administration Review, 64(3), 363-371. http://dx.doi.org/10.1111/j.1540-6210.2004.00380.x

Knickman, J., \& Stone, R. (2007). The Public/private Partnership Behind the Cash and Counselling Demonstration and Evaluation: Its origins, challenges and unresolved issues. HRS: Health Service Research, 41(1, Part II), 362-374. http://dx.doi.org/10.1111/j.1475-6773.2006.00675.x

Lasker, D., Weiss, E., \& Miller, R. (2001). Partnership Synergy: A Practical Framework for Studying and Strengthening the Collaborative Advantage. The Milbank Quarterly, 70(2), 79-205.

Malmborg, F. (2003). Conditions for Regional Public-Private Partnerships for Sustainable Development Swedish Perspectives. European Environment, 13, 133-149. Retrieved from www.interscience.wiley.com

Neal, E. (2010). Playtime Preservation: Public Private Partnerships in Public Land Management. Unpublished Dissertation. Boston, Massachusetts: Northeastern University.

Noble, G., \& Jones, R. (2006). The Role of Boundary-Spanning Managers in the Establishment of Public-Private Partnerships. Public Administration, 84(4), 891-917. http://dx.doi.org/10.1111/j.1467-9299.2006.00617.x

Parker, D. (2012). The Private Finance Initiative and Intergenerational Equity. Intergenerational Foundation. London. Retrieved from www.if.org.uk

Pessoa, A. (2008). Public-Private Partnerships in Developing Countries: Are Infrastructures Responding to the new ODA Strategy? Journal of International Development, 20, 310-325.

PMU. (2009). A New Era in the Management of Water in Jordan. Al Myyah News. Issue 2, Sping, 2009. Retrieved from http://www.pmu.gov.jo/Portals/0/PMU/Almeyyah\%20News.pdf

PMU. (2010). Samra Waste Water Treatment Plant in Jordan. Al Myyah News. Retrieved from http://cupe.ca/updir/Flawed_Failed_Abandoned__Final.pdf

Read, J. (2008). Public sector still managing PFI projects badly, says PAC. Public Finance. Retrieved from http://www.publicfinance.co.uk/news/2008/public-sector-still-managing-pfi-projects-badly-says-pac/

Russel, V. (2008). Skills deficit still an issue, warns Leigh. Retrieved from 
http://www.publicfinance.co.uk/news/2008/skills-deficit-still-an-issue-warns-leigh/

Schaeffer, P., \& Loveridge, S. (2002). Toward an Understanding of Types of Public-Private Cooperation. Public Performance \& Management Review, 26(2), 169-189. http://dx.doi.org/10.1177/1530957602238261

Siemiatycki, M. (2010). Developing Transportation Infrastructure through Public-Private Partnerships. Journal of the American Planning Association, 76(1), 43-58. http://dx.doi.org/10.1080/01944360903329295

Stake, R. (1998). Case Studies. In N. Denzin, \& Y. Lincoln (Eds.), Strategies of Qualitative Inquiry (pp. 86-109). Thousand Oaks: Sage Publications.

Teisman, G., \& Klijn, E. (2002). Partnership arrangements: Governmental rhetoric or governance scheme? Public Administration Review, 62(2), 197-205. http://dx.doi.org/10.1111/0033-3352.00170

Vining, A., \& Boardam, A. (2008). Public-Private Partnerships in Canada: Theory and evidence. Canadian Public Administration, 51(1), 9-44. http://dx.doi.org/10.1111/j.1754-7121.2008.00003.x

Weihe, G. (2008). Public-Private Partnerships and Public-Private Value Trade-Offs. Public Money \& Management, (June ), 153-159. http://dx.doi.org/10.1111/j.1467-9302.2008.00637.x 